This is the peer reviewed version of the following article: Gardner, J. and McNally, H. (1995), Supporting schoolbased initial teacher training with interactive video. British Journal of Educational Technology, 26: 30-41, which has been published in final form at https://doi.org/10.1111/j.1467-8535.1995.tb00118.x. This article may be used for non-commercial purposes in accordance with Wiley Terms and Conditions for self-archiving.

\title{
Supporting School-based Initial Teacher Training with Interactive Video
}

\author{
John Gardner and Helena McNally \\ The Queen's University of Belfast
}

Correspondence:

Dr John GARDNER

Reader in Education

School of Education

The Queen's University of Belfast

69 University Street

BELFAST BT7 1HL

Northern Ireland

Tel: $\quad+44232245133 \times 7128$

Fax: $\quad$ +44232 239263

e-mail: j.gardner@qub.ac.uk 


\title{
John Gardner and Helena McNally
}

John Gardner and Helena McNally are at the School of Education, The Queen's University of Belfast, Belfast BT7 1NN

\begin{abstract}
This paper reports on a project commissioned by the National Council for Educational Technology and designed to investigate the potential for interactive video to support students and mentors in school-based initial teacher training (ITT). Its results derive from an empirical study in 26 schools, currently using interactive video in staff development. The work focused on three parallel questions relating to the new models of school-based training: what are the training needs of the students, their mentors and ITT tutors?; what features of interactive video make it a feasible and appropriate means of distance learning in this context? and how is interactive video currently being used in schools' staff development? A primary concern was to investigate the potential of interactive video to offer a consistent core of training that would cover a breadth of training experiences, regardless of the student's placement. Using the Quality Management in Schools interactive video disks (QMS I and II 1990/91) as the focus, the modes of usage and perceived value of interactive video in staff development are considered. The report concludes by commenting on the potential of interactive video for ITT.
\end{abstract}




\section{Supporting School-based Initial Teacher Training with Interactive Video}

\section{Evaluation context}

Since the Summer of 1992 (DFE 1992) new ITT models have clearly implied that students must spend anything from 66 to $100 \%$ of their time in their placement schools. The teacher education community has expressed a variety of concerns about these changes but prime amongst them is the common view (supported by research - Draper et al 1992) that some schools, as training environments for newly-qualified teachers, are not always properly prepared for the rôle. Even with the most meticulous planning and preparation the possibility must exist that a particular ITT student's placement may turn out to be unsuccessful in terms of the quality and breadth of training experienced. While on teaching placement, students should therefore have an entitlement to a core training provision that is independent of their placement school. The 'curriculum' of this core training continues to develop (Whitty and Willmott 1991, SOED 1992) and much progress has been made (DENI 1993) in identifying the appropriate location (institution or school) for the development of each element of the student teacher's competence. The guiding principles for this core training are that it should be consistent for all students and that it should provide exposure to a broad range of training experiences, regardless of the students' placements. Clearly this also has implications for the training of school-based mentors and ITT tutors. Work carried out in England (for example see Shaw 1992, McIntyre et al 1993) and in Scotland (see Cameron-Jones and O'Hara 1993) has made considerable progress, during the last two to three years, in identifying the operational characteristics of mentor models for ITT. In so doing they have also contributed to a fuller understanding of the training needs of mentors, ITT tutors and student teachers. The main training issues are considered briefly below.

\section{Mentor training needs}

Mentor teachers play the primary rôle in supervising, observing and assessing student teachers' teaching and related work. Much of this mentoring function is familiar to teachers who have regularly 'supervised' students placed with them under previous ITT models. It is reasonable to assume that most mentors come from the ranks of these experienced people but the new model does imply both a closer relationship (mentor/student) and a more formal and therefore less familiar responsibility for the student's development and assessment. A degree of training is also needed for both mentors and ITT tutors to ensure consistency in their respective dealings with the students particularly in the interpretation and application of assessment criteria.

Quality, consistency and breadth in students' training experiences 
One of the main problems in a school-based ITT model is that the extent of contact with other teacher educators in tutorials, in focused workshops and in special tuition programmes (such as cross-curricular themes, special needs and so on) is likely to be restricted. Interaction with their peers, particularly those in their cognate teaching areas, is also likely to be much more limited. These issues give rise to the concern that the new training models should ensure that each student, regardless of their school placement, is exposed to a broad range of teaching methods and styles, of pupil and class management strategies and to a consistent, structured study and discourse on topical issues, relevant to their teaching.

With this focus of concern on consistency and breadth of experience, the rôle interactive video might play in ITT is considered below.

\section{Interactive Video Approaches to Training}

In contrast to the relatively rudimentary control of video tape systems and the lack of control of broadcast material, computer controlled interactive video systems are characterized by fine and relatively instantaneous control over stopping, replaying and so on. In addition, and quite uniquely, such systems usually also enable the students to store their responses to the material directly on the computer for later analysis. The perceived benefits of interactive video for ITT are developed further in the next section (for examples of interactive video usage in conventional 'institutional' ITT see Wright and Dillon 1990 and Harvard 1990).

In the context of the new ITT models, any whole-group training issues, which cannot be addressed during any period the students spend at their institution, need to be tackled in their placement schools. Depending on the nature and scope of the training, however, it may not be realistic to expect the training to be provided by the school and it may not be possible to send a team of trainers around the schools to do it. Industry and commerce have long faced the same problems with distributed branch-based workforces and many organizations have espoused interactive video as a major alternative to conventional tutor-led training. The arguments supporting the use of interactive video in these sectors are presented below in the context of initial teacher training.

\section{Cost benefits}

The cost benefits of distance learning have been widely rehearsed in industry and commerce. It is relatively easy in teacher education contexts to calculate the cost of an in-service course in terms of paying for such items as the training location, the tutors' fees, any necessary resources, substitution, travel and subsistence costs for the teachers and so on. It would even be possible to estimate compensatory costs relating to the disruption to teaching that attendance at a course entails. A 
superficial comparison with the cost of simply sending the distance learning materials to the schools makes the cost benefits of distance learning look very attractive. Most rigorous comparisons, however, will use accurate costings for the development of the materials, spread over their projected usage lifetimes, and for supporting the trainees with help-lines, tutorial sessions and so on.

\section{Quality of training}

The ability to illustrate complex social and interpersonal processes or events, in familiar televisionstyle dramatized enactments, is an added value of interactive video training that is difficult to challenge. Aside from the 'real thing', the only comparable activities are tutor-led rôle play sessions or studies of similar enactments on conventional videotape. As with other distance learning materials, interactive video disks and their accompanying software and documentation, represent collections of standard materials that all students can be furnished with and expected to use. The training approach and objectives can therefore be kept consistent across a widely distributed training population.

\section{Interactivity}

As mentioned above interactive video enables students to control video presentations quickly and conveniently. Its main attribute, however, is its facility to generate a degree of challenge for the students by posing questions or problems for them or by enabling them to choose what they do next. Their answers or choices are evaluated according to pre-determined (ie. pre-programmed) 'response analysis' strategies that direct them along pathways containing video sequences appropriate to their response or choice. Aside from this interaction between the student and the machine, many of the current implementations of interactive video encourage group interaction between the members of a group using the system (see Figure 1).

\footnotetext{
$* * * * * *$ FIG 1 HERE $* * * * * *$
}

\section{Tailored materials}

Interactive video material can usually be tailored to particular students' needs by judicious structuring of the programme of study, using in-built course specification tools. This might be accomplished by the mentor in consultation with the ITT tutor. Weaknesses in, for example, questioning technique can be addressed with suitable video material for one student while the same 
disk used by another student could be directed at fostering an awareness of slow learners' needs. A particularly useful feature is the twin audio tracks that interactive video disks have. It is possible to tailor the same video sequence for either a mentor or student audience, simply by providing a different voice-over. Many of the most recently released videodisks (eg. Skills for Appraisal Interviewing and TSM both 1993) incorporate this dual purposing.

\section{Assessment}

Any course of study involving interactive video can contribute to the formative and summative assessments of the students by making use of the computer to store both the students' 'off the cuff' reactions to the material (for discussion during training sessions or for development in feedback debriefing sessions) and their more formal assignment work. Reports on work done and progress made can be generated for student, mentor and tutor alike and can be retained for assessment evidence as appropriate.

\section{'Piggy-backing' time and hardware}

An often quoted advantage of computer based training is the ability to schedule training in time that is otherwise 'free' (eg. non-teaching time) and on hardware that is not otherwise being used. In the case of student teachers, time for such training is likely to be a feature of their normal timetable, probably in small training groups.

\section{Distribution}

Interactive video training materials are relatively easy to distribute by post - the disks and their supporting software and documentation can be sent directly to the students' places of work ie. their placement schools. While the video disks themselves cannot be altered it is a relatively simple matter to create alternative or updated courses of study by sending revised software or documentation directly to the schools.

\section{Variety of training contexts}

The major strength of video based training materials is the variety of contexts they can address. Video can be used to illustrate social and interpersonal events in a manner that only rôle-play, in conventional training, comes close to emulating. Some of the training contexts that are appropriate for interactive video approaches are outlined below.

\section{Rôle relationships}


It can take some considerable time for student teachers to become accustomed to the various rôles that different types of staff and pupils play in a school. Most areas of professional practice, relating to a teacher's duties and their working relationships, can be illustrated in video and studied by the students. Video presentations can be designed to address the nature of the relationships between the teacher and the pupils (inside the classroom, for example, being a little bit different from field trips) and between the teacher and other teachers. The rôles of senior members of staff can be explained to help give meaning to the organizational features of running a school. In the context of the school's relationships with parents, video simulations of teacher-parent dealings can also assist student teachers in developing their awareness of these issues.

The relationship between the mentor, the student and the ITT tutor, under the new models of training, could also be an important focus for interactive video treatment. A particular strength of interactive video is that the same video material could be made to address both the trainer and trainee perspectives simply by tailoring, for each audience, the alternative audio tracks and the computer based presentation (ie. the text that the computer overlays on the video pictures).

\section{Familiar and unfamiliar circumstances}

Interactive video can address the need for students to be aware of different strategies in dealing with familiar situations. It may be that they quickly develop a method of coping with routine circumstances in a manner that is not necessarily the most appropriate. The use of video, to facilitate the analysis of such situations, can assist the students to evaluate different strategies and perhaps adopt more appropriate and successful approaches.

Student teachers are called upon to face many situations that serving teachers, by virtue of their experience, have no trouble in dealing with. Many such situations may well have a discipline dimension but there may also be instances where, for example, pupils might require minor first-aid (not necessarily from the student), where a pupil has particular learning difficulties or where external circumstances disrupt a lesson. While there is no substitute for experience there is also no argument against making students aware of the kinds of situations that might arise. Video simulations of appropriate circumstances or events can provide the students with insights and a breadth of 'simulated experience' that can prove valuable when having to cope with the 'real thing'. 


\section{Sensitive contexts}

Some aspects of a person's working practices (students, mentors and tutors alike) can prove difficult for a staff development tutor to broach with them. Very often these occur in the area of communication/interpersonal skills but they can also arise in other contexts, particularly in the case of students. Awkward situations might arise, for example, in presentation areas such as dress code or the use of grammar in speech. While there is the argument that ITT tutors are experienced in handling such matters it now falls increasingly to mentors to deal with them. Interactive video sequences can provide opportunities for the mentor to evaluate strategies for the necessary interventions while the same material can be used to highlight inappropriate behaviour for the students (again exploiting the flexibility of the computer based overlays and the twin audio tracks).

An interesting extension to this approach, made possible by interactive video, is to provide both types of trainee (mentors and students) with a 'voice-over' of the thought processes that the other is engaged in. This serves to highlight the many sensitive issues behind the intervention dialogue, including the diplomacy concerns of the mentor and the deferential constraints on the student.

\section{Survey of interactive video in staff development}

This section reports upon a study into the use of interactive video for staff development. The research had a schools' focus, involving interviews with teachers in a sample of 26 Northern Ireland secondary-level schools. The sample was made up of schools involved in the first and second pilot phases of a local initiative to use interactive video in school-based management training (RTU 1991,1992). The interactive video material comprised the two disks Quality Management in Schools (QMS) Units I and II. These disks use video 'vignettes' to stimulate discussion and reflection in a variety of contexts including dealing with complaints, conducting meetings, 'What would you do?' scenarios, the concept of total quality management, performance indicators, team building, curriculum monitoring and reporting to parents.

All but one of the 'pilot' schools agreed to participate in the survey and a small number of schools, which had taken up QMS independently, were also involved. Some of the schools had allocated a member of staff as QMS 'coordinator' while in others the person in charge of staff development took on the QMS training as part of their remit. These people were interviewed in each school and in most cases one or more of the 'trainees' was also interviewed.

The schools ranged in size from 19 to 165 members of staff (six schools had less than 25 members of staff, 17 had between 25 and 70, and six had more than 70 members of staff). Of the 26 schools involved in the survey, 19 had existing interactive video equipment with a QMS Unit I disk and 
documentation (seven of the schools had had to return their equipment to their local authority). QMS Unit II had not yet reached eight of the schools. None of the schools had any other form of computer based training materials.

As part of the original pilot study, organised by the Regional Training Unit (RTU), induction training was provided at all levels: two days for the QMS coordinators, a half-day for the school principals, and a half day for the school technicians along with their coordinators. The personnel involved in coordinating the QMS activities in the schools were mainly senior personnel: two were principals, 17 were vice-principals, two were senior teachers and five were either heads of department or heads of year. About half the group (11 in all) had overall responsibility for staff development and all but one had been on RTU training courses. In most cases the staff who were to undertake the training, mainly heads of departments, were identified by the principal or the senior management team while in seven of the schools the training was open to anyone who put themselves forward for it.

\section{Operational features of interactive video usage}

The respondents were asked to describe various aspects of their organizational and operational strategies for using QMS and the issues are summarized below.

\section{Location}

In most of the schools the QMS system was sited in a dedicated room; usually a staff study room but also occasionally in an office shared by the schools' heads of department. The primary concern was to choose a location that would provide for undisturbed working and the privacy to deal with matters in a frank and open manner.

Accessibility was an initial but quickly remedied problem in some schools. In these cases the main complaint was remoteness from the main areas of work of the trainees. In five schools staff needed to book the facility while in four others a key was needed to gain access. Neither constraint appeared to viewed as a problem by the coordinators concerned. Aside from one school, in which the system was only available on INSET days, all of the schools facilitated access at any time. The use of after school directed time (ie. the period between the end of lessons and the official end of the school day) was the most common timetabling model. 


\section{Debriefing}

Debriefing is an important element of working with QMS and in about half of the schools the coordinator did carry it out. Debriefing was not considered a problem in terms of time as in all cases directed time or exceptional closure time was given over to it. The existence of debriefing seemed to depend on the degree of systematic approach to the training. For example, in cases where the work was planned out, personnel were targeted and reports were made to the senior management team, it was very likely that debriefing did feature strongly in the process. Where reporting to the senior management team existed it was usually relatively informal (verbal) and in only a very few cases was it the subject of continuous monitoring as part of a staff development programme.

\section{Technical issues}

A number of schools reported initial teething problems that varied from parts missing to unexplained system 'crashes'. None of these persisted for very long and had been ironed out relatively quickly either by the school's own technicians or by one of the support agencies.

QMS offers a 'notepad' facility for trainees to record (by typing) their comments and answers to questions (the latter being of the open type requiring reflection and discussion). The facility to provide each user or group of users with private storage files also allows the trainees some measure of privacy for candid responses. This facility was used by most of the coordinators but it was not clear that the 'privacy' was needed and a number of them, who professed to being less IT competent than they would have wished to be, did complain that the processes involved in setting it up caused them some problems.

When asked why so little use was made of the note-pad facility a variety of reasons were offered. Most of the users were happy to control the presentation, using the mouse with the menu buttons and so on, but were much more reluctant to try anything more complicated. Lack of typing skill was a major factor as many did not wish to be seen to be 'hunting and pecking' along the keyboard in front of their group. Pen and paper notes were frequently kept and a number of respondents cited this as being convenient and adequate. A common reason for the lack of use of the note-pad was the perception of the system as providing stimulus for the discussion of issues. This discursive function, in contrast to any notion of appraisal or analysis of the work done, was viewed as its prime function. 


\section{Value of interactive video in staff development}

With only a small number of exceptions the value of QMS in staff development was enthusiastically endorsed by the majority of the respondents. Typical comments pointed to its timeliness in stimulating staff development issues, its value in introducing otherwise awkward training topics and its ability to motivate trainees. Many considered it to be enjoyable to use, to provide opportunities for reflection on topical issues, to be especially suitable for small groups and so on. In many cases its usage was not formally structured but where staff development was a formal and systematic feature of the school's operation, interactive video was closely integrated into the overall programme.

\section{Content}

None of the schools reported any major difficulties with the content of the disks. The stereotyping of some of the characters was felt to be exaggerated but was nonetheless considered by all respondents to be acceptable as an efficient means of focusing on the issues raised. In some schools there was a feeling that the problem issues, and the ways in which they were depicted, had a tendency to being too grammar school oriented. The problems were considered to be relatively low in priority in these schools as they felt they had more pressing types of problems, particularly in pupil behaviour contexts. There was general agreement, however, that the various scenarios did draw out issues of sufficiently broad interest to stimulate productive discussion.

\section{Stimulating discussion}

The ability of the QMS disks, and by implication interactive video, to stimulate discussion was a universally acclaimed attribute. A number of important features were commented upon. Interactive video-based training was considered a refreshing alternative to (but not necessarily a substitute for) external INSET. The school-based approach placed the discussions squarely in an 'our school' rather than an 'any school' context. It was considered useful to compare the strategies illustrated in the video with "how we would do it" but it was noted as being particularly valuable to hear colleagues' views on matters of mutual importance.

The ability to initiate discussion on controversial or sensitive topics was also widely appreciated. Respondents spoke of the 'Trojan Horse' approach of using interactive video to broach difficult topics without being seen to be doing it deliberately in response to real circumstances. Instances of existing problems were alluded to in several schools including difficulties with inefficient heads of department or members of staff not 'pulling their weight'. A variation on this theme was the 'Bogeyman' approach that described the introduction of potentially sensitive discussion topics (not 
necessarily linked to any existing problems) as being made easier because the person in charge of staff development could attribute blame for its introduction to the machine!

Only one significant criticism was made about the manner in which the content was presented. Some respondents expressed the view that they would have liked to have had some 'concrete' answers to some of the questions posed but most took the view that much of the more open material needed a more senior person (than those in the training group) who would be able to give an experienced appraisal of the strategy options available.

\section{Value for ITT and induction training}

Despite the overall favourable views expressed about QMS, several of the respondents felt that it had little direct relevance to their schools' training programme although only one considered externally provided INSET to be better (the main reason being the opportunities to exchange ideas and discuss mutual problems and their solutions with colleagues in other schools). The majority of respondents considered that QMS would have much value for student and induction teachers. The material could give them valuable insights into schools' management structures and relationships and into classroom-based issues such as relationships with pupils. Consideration of school specific procedures, such as those involved in record keeping, could also be stimulated by the materials even when the strategies proposed were quite different from those in the school. A variety of topics was suggested as being suitable for interactive video approaches in ITT and these are listed in the next section.

\section{Areas suitable for interactive video training in ITT}

The topics which the respondents felt could be supported by an interactive video approach are listed below but it should be emphasized that these represent areas of development that require practice and should not be left exclusively to interactive video based training. It is envisaged that suitable video material could be produced to exemplify the relevant issues through highlighting good or bad practice as appropriate.

Teaching and classroom management styles:

- routines for beginning a class;

- techniques for establishing the purpose of a lesson;

- asking questions;

- explaining matters;

- working in mixed ability environments; 
- working in active learning environments;

- techniques for consolidating pupils' learning;

- routines for ending a class;

- dealing with misbehaviour;

- avoiding and resolving conflict;

- carrying out assessments;

- keeping records;

- seeing how other subjects are taught.

Outside the classroom:

- managing field trips, outings and so on;

- relating to pupils in the playground, in sports contexts and so on;

- dealing with misbehaviour (smoking, litter, fights and so on);

- planning lessons (pace, sequence and so on);

- planning resource needs;

- marking homeworks;

- dealing with parents.

Relationships with colleagues:

- seeking advice from senior colleagues;

- contributing to staff and departmental meetings;

- communicating with colleagues (eg. informing colleagues of intentions to withdraw pupils for rehearsals, sports practice, matches and so on).

\section{Impact on working practice}

When asked about the impact that using QMS had had on their working practices, all of the trainee respondents (14 in total) considered that they now put much more thought into their work. For the majority of them, this had resulted in them changing the way they do things. Some felt they were better organized, that they approached their work in a more logical 
manner, that they consulted their staff more and that they organized some of their responsibilities differently.

\section{Summary}

The survey strongly suggests that the prime concerns of a distributed training system, assuring quality, consistency and breadth of experience in many different school-based contexts, can be addressed using interactive video training materials. The materials are easily disseminated and can contribute to a core of training in a manner that would be consistent for a widely distributed trainee population. Respondents in the surveyed schools wholeheartedly endorsed the use of interactive video in stimulating reflection and discussion on a wide range of complex educational issues and processes. They commented on the value of interactive video in introducing otherwise awkward training topics, in stimulating staff development and in motivating trainees. Many considered it to be enjoyable to use, to provide opportunities to reflect on topical issues and to be particularly suitable for small group training. Given appropriate video materials and an appropriate training approach it would seem reasonable to conclude that interactive video materials can raise students' awareness of different teaching styles, classroom management strategies, professional relationships and so on. This can be achieved independently of the quality and breadth of experience that their school placement offers them.

It is unlikely that students will approach interactive video training, or any other type of training, in a serious manner without some form of incentive. The normal 'incentive' is to make the activity mandatory, by requiring appropriate assignments to be completed for assessment. If interactive video is to provide a core of training that is consistent and that covers a broad range of experiences, then it is essential that the work be formally assessed as part of the students' ITT certification.

\section{Acknowledgements}

The authors would like to acknowledge the National Council for Educational Technology for their sponsorship of this research. Thanks are also due to the schools and professional bodies who facilitated the work.

Cameron-Jones, M. and O’Hara, H. (1993) The Scottish Pilot PGCE (Secondary) Course 1992/93 Moray House Institute, Edinburgh

DENI (1993) Reports of the ITT Review Working Parties (I, II, III and IV) Department of Education for Northern Ireland, Bangor 
DFE (1992) Initial Teacher Training (Secondary Phase) Circular 9/92 Department for Education HMSO, London

Draper, J., Fraser, H., Smith, D. and Taylor, W. (1992) A Study of Probationer Teachers Moray House Institute,

Edinburgh

Harvard, G. R. (1990) Some exploratory uses of interactive video in teacher education: designing and presenting interactive video sequences to primary student teachers Education and Training Technology International 271 155-163

McIntyre, D., Hagger, H. and Wilkin, M. (Eds) (1993) Mentoring: Perspectives on School-based Teacher Education Kogan Page, London

Shaw, R. (1992) Teacher Training in Secondary Schools Kogan Page, London

SOED (1993) Guidelines for Teacher Training Courses Scottish Office Education Department, Edinburgh

RTU (1991) Evaluation of Pilot Project (QMS) 1990/91 Regional Training Unit, Belfast

RTU (1992) Evaluation of Pilot Project (QMS) 1991/92 Regional Training Unit, Belfast

Whitty, G. and Willmott, E. (1991) Competence-based teacher education; approaches and issues Camb. J. of Education 213 309-318

Wright, B. and Dillon, P. (1990) Some applications of interactive video in initial teacher training Education and Training Technology International $27143-50$

Interactive video training materials for teacher training:

TSM (1993): Teaching Secondary Maths Scottish Interactive Technology Centre, Moray House, Edinburgh Skills for Appraisal Intervieing (1993) : Scottish Interactive Technology Centre, Moray House, Edinburgh QMS I and II (1990-1) : Quality Management in Schools Northern Ireland Centre for Learning Resources, Belfast 


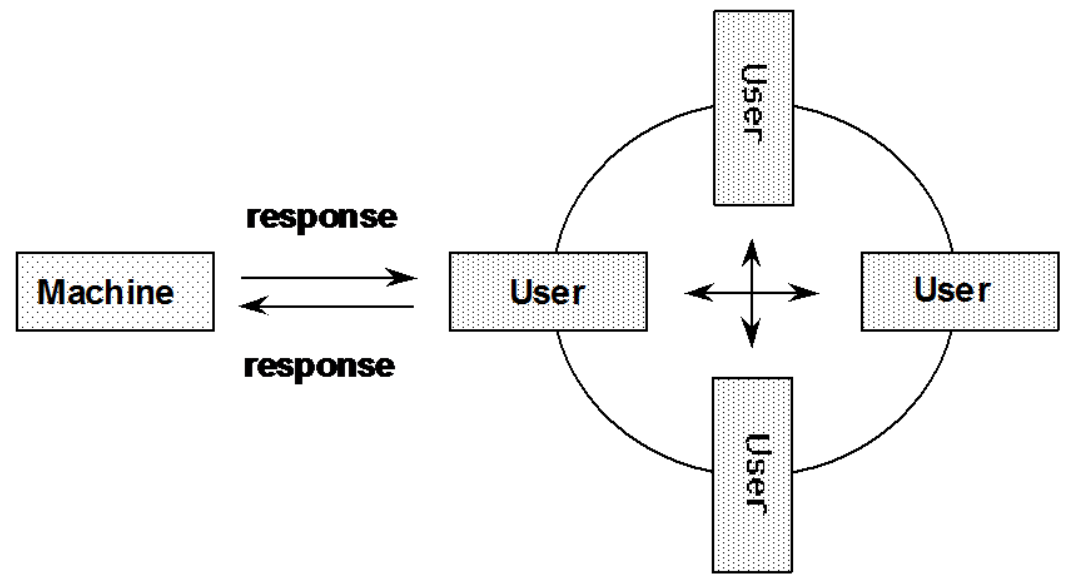

Figure 1: User-Machine and User-User Group Interaction with Interactive Video 